\title{
Differences in coping strategies in adult patients with bipolar disorder and their first-degree relatives in comparison to healthy controls
}

\author{
Diferenças entre as estratégias de coping em pacientes adultos com transtorno \\ bipolar e seus familiares em comparação com controles saudáveis
}

Kelen Patrícia Bürke Bridi, Ana Claudia M. Loredo-Souza, Adam Fijtman, Mirela Vasconcelos Moreno, Márcia Kauer-Sant'Anna, Keila Maria Mendes Ceresér, Mauricio Kunz

\begin{abstract}
Introduction: The objective of this study was to compare patients with bipolar disorder (BD), their first-degree relatives and a group of healthy controls in terms of use of adaptive and maladaptive coping strategies, exploring differences between specific types of strategies and their correlations with clinical variables.

Methods: This was a cross-sectional study enrolling 36 euthymic patients with BD, 39 of their first-degree relatives and 44 controls. Coping strategies were assessed using the Brief COPE scale.

Results: Significant differences were detected in the use of adaptive and maladaptive strategies by patients, their firstdegree relatives and controls. Patients used adaptive strategies less often than the patients' relatives $(p<0.001)$ and controls $(p=0.003)$. There was no significant difference between firstdegree relatives and controls $(p=0.707)$. In contrast, patients $(p<0.001)$ and their relatives $(p=0.004)$ both exhibited higher scores for maladaptive coping than controls. There was no significant difference regarding the use of maladaptive strategies between patients and their relatives $(p=0.517)$.

Conclusions: First-degree relatives were at an intermediate level between patients with $\mathrm{BD}$ and controls regarding the use of coping skills. This finding supports the development of psychosocial interventions to encourage use of adaptive strategies rather than maladaptive strategies in this population. Keywords: Coping, Brief COPE, bipolar disorder, first-degree relatives.
\end{abstract}

\begin{abstract}
Resumo
Introdução: $\mathrm{O}$ objetivo deste estudo foi comparar os pacientes com transtorno bipolar (TB), seus familiares de primeiro grau e um grupo de controles saudáveis em termos de uso de estratégias adaptativas e não adaptativas, explorando diferenças entre tipos específicos de estratégias e suas correlações com variáveis clínicas.

Métodos: Estudo transversal, envolvendo 36 pacientes com TB eutímicos, 39 familiares de primeiro grau e 44 controles. As estratégias de enfrentamento foram avaliadas usando a escala Brief COPE.

Resultados: Foram detectadas diferenças significativas no uso de estratégias adaptativas e não adaptativas por pacientes, seus familiares e controles. Os pacientes usaram estratégias adaptativas com menos frequência do que os familiares $(p<0,001)$ e controles $(p=0,003)$. Não houve diferença significativa entre familiares dos pacientes e controles $(p=0,707)$. Por outro lado, os pacientes $(p<0,001)$ e seus familiares $(p=0,004)$ exibiram pontuações mais elevadas para coping não adaptativo em relação aos controles. Não houve diferença significativa quando os pacientes foram comparados com seus familiares $(p=0,517)$. Conclusões: Familiares de primeiro grau estavam em um nível intermediário entre pacientes com TB e controles no que diz respeito ao uso de habilidades de enfrentamento. Esta descoberta apoia o desenvolvimento de intervenções psicossociais para incentivar o uso de estratégias adaptativas em vez de estratégias inadequadas nessa população.
\end{abstract}

Descritores: Coping, Brief COPE, transtorno bipolar, familiares de primeiro grau.

Programa de Pós-Graduação em Psiquiatria e Ciências do Comportamento, Universidade Federal do Rio Grande do Sul (UFRGS), Porto Alegre, RS, Brazil. Laboratório de Psiquiatria Molecular, Hospital de Clínicas de Porto Alegre (HCPA), UFRGS, Porto Alegre, RS, Brazil.

Submitted Nov 27 2017, accepted for publication Mar 202018.

Suggested citation: Bridi KPB, Loredo-Souza ACM, Fijtman A, Moreno MV, Kauer-Sant'Anna M, Ceresér KMM, et al. Differences in coping strategies in adult patients with bipolar disorder and their first-degree relatives in comparison to healthy controls. Trends Psychiatry Psychother. 2018;40(4):318-325. http:// dx.doi.org/10.1590/2237-6089-2017-0140 


\section{Introduction}

Bipolar disorder (BD) is a multidimensional condition, involving a complex and dynamic interaction between biological and psychosocial factors. Although pharmacotherapy is the first-line treatment for $B D$, psychosocial interventions are also important tools for managing emotional and behavioral factors during the course of the disease. ${ }^{1,2} \mathrm{BD}$ is associated with significant impairment in work, family and social life, beyond the acute phases of the illness. Factors that appear to increase the risk of poor functioning and disability in patients with $\mathrm{BD}$ are mainly subsyndromal symptoms and neurocognitive impairment. ${ }^{3} \mathrm{BD}$ is associated with markers of psychosocial dysfunction that refer to a person's ability to function socially and professionally and live independently. Patients with BD may experience severe dysfunction in different domains of life, such as work productivity, social activities, and autonomy. The condition is also associated with higher mortality rates and causes high treatment costs and considerable emotional distress for patients and their families. ${ }^{4}$ The association between stressors and precipitation of bipolar episodes has been clearly documented. ${ }^{5}$

Coping strategies can be useful for dealing with some of these factors. Coping can be defined as thoughts and behaviors used to manage the internal and external demands of situations appraised as stressful. ${ }^{6}$

Coping strategies can be conceptualized as maladaptive or adaptive. For example, active coping strategies are understood to be adaptive, contributing to a better psychosocial functioning, ${ }^{7}$ whereas maladaptive coping strategies, such as rumination about negative states, are linked to increased depression. ${ }^{8}$ In addition to their influence on the course of the disease, different coping strategies (e.g., low levels of acceptance and high levels of denial) have been associated with poor adherence to medication in BD I. ${ }^{9}$

The use of coping strategies has been recognized as an important mechanism in BD clinical outcomes that can aid in preventing the emergence of affective disorders in subsets of the population at greater-thanaverage risk of developing such a disorder. ${ }^{10}$ Studies have investigated how the use of coping strategies can impact on BD. ${ }^{11-13}$

Studies of coping in BD suggest that the way in which patients face the prodromes of mania and also their ability to recognize early signs of depression make a significant contribution to their level of social functioning. ${ }^{11}$ Bipolar patients tend to use a less active and more avoidance-based style of coping in reaction to stress than people in the general population ${ }^{14}$ and exhibit greater reliance on maladaptive coping strategies and lesser utilization of adaptive strategies in response to negative events than their unaffected biological relatives and than healthy controls. ${ }^{13,15}$

The risk of first-degree relatives developing $B D$ is approximately 10 -fold higher than that of the general population. ${ }^{16}$ Studies have shown that the family members of patients with BD have stress levels that are as high as those observed in the caregivers of people diagnosed with schizophrenia ${ }^{17}$ and higher than the levels of people caring for relatives with unipolar depression. ${ }^{18,19}$ Maladaptive coping strategies are observed in family environments marked by high levels of conflict and excessive control, and by low levels of cohesion and emotional support, whereas adaptive coping strategies are more common in family environments that are cohesive and supporting, with low levels of conflict and control.20 The children of bipolar parents exhibit an increased risk of developing psychiatric pathologies or dysfunctions and a profile of ineffective coping strategies. ${ }^{21}$ Disruptive behaviors during childhood, anxiety and early-onset depression can be considered markers of risk for BD in high-risk group individuals. As such, coping strategies can play an important protective role throughout the course of the disease. ${ }^{22}$

It is therefore necessary to investigate the manner in which patients and family members employ coping strategies and how to intervene to achieve better management of these factors, understanding which groups need interventions to help patients and relatives to better manage stress situations. Few studies have investigated coping in BD and no studies have assessed coping in adult first-degree relatives of bipolar patients.

In view of the importance of environmental factors in the course of this disease, the objective of this study was to investigate coping in $\mathrm{BD}$, comparing patients with $\mathrm{BD}$ with their first-degree relatives and a group of healthy controls in terms of their use of adaptive and maladaptive coping strategies. The secondary objective is to explore differences between specific types of strategies and correlations with clinical variables. Our hypothesis is that groups of bipolar patients and relatives will present greater use of maladaptive strategies compared to the control group.

\section{Methods}

\section{Population and procedures}

This was a cross-sectional study with sampling by convenience. Thirty-six outpatients with BD, 39 unaffected siblings, and 44 healthy subjects were included. Patients with BD were recruited from among those being treated at the $B D$ program of Hospital de Clínicas de Porto Alegre (HCPA), a public health service 
in southern Brazil; their siblings were also enrolled. Inclusion criteria for patients were as follows: diagnosis of type I BD according to the Portuguese version of the Structured Clinical Interview for DSM-IV Axis I Disorders (SCID-I), euthymic, on pharmaceutical treatment for at least 45 days, scores $\leq 7$ on the Hamilton Depression Rating Scale (HAMD) and the Young Mania Rating Scale (YMRS), no diagnosis of neurological disease or serious clinical disease. Patients' siblings were recruited if they were free from any psychiatric diagnosis according to the Diagnostic and Statistical Manual of Mental Disorders, 4th edition (DSM-IV), had HAMD and YMRS scores $\leq 7$, were free from neurological disease and serious clinical disease and provided informed consent in writing.

Volunteers for the control group were recruited among people donating blood to the blood bank at HCPA. Inclusion criteria for the control group were as follows: no history of psychiatric diagnoses according to the DSMIV, HAMD and YMRS scores $\leq 7$, no neurological disease or serious clinical disease, no prior history of psychiatric disorders, no history of psychiatric disorders in firstdegree relatives and provision of informed consent in writing. Controls underwent in-depth clinical interviews with well-trained psychiatrists, using a short form of the SCID-I. All patients and controls signed informed consent forms before taking part in the study, which had in turn been submitted to and approved by the research ethics committee at HCPA (protocol no. 10-0503).

\section{Instruments}

Coping strategies were evaluated using a version of the Brief COPE scale, which assesses 14 adaptive and maladaptive styles derived from theoretical studies on coping, adhering partly to the model developed by Lazarus \& Folkman ${ }^{6}$ and partly to the behavioral self-regulation model. ${ }^{23} \mathrm{~A}$ version of the instrument previously adapted for Portuguese was used.24 The authors of the scale ${ }^{25}$ are interested in the role that individual differences can have in coping and recognize that there are certain styles of coping that integrate a repertoire of relatively fixed strategies, used through time and circumstances. The approaches that integrate the issues of individual disposition approximate the trait theory and focus on coping strategies that tend to be used by individuals in varied stressful situations. These approaches can be evaluated as measures of selfresponse, questioning the habitual way of responding to stressful environments. ${ }^{24}$

The instrument asks participants to respond indicating how often they normally react to stressful situations using a list of different strategies. The response choices lie along a 4 -point scale ( $1=$ never; 2 =occasionally; 3 =very often; and 4 =always). According to Carver, ${ }^{26}$ the scale can be used in accordance with authors' requirements. For the purposes of analyzing Brief COPE data, coping strategies were classified as either adaptive or maladaptive. ${ }^{13}$ Adaptive strategies included active coping, planning, use of emotional support, use of instrumental support, positive reframing, acceptance, religion, and humor. Maladaptive strategies include venting, denial, substance use, behavioral disengagement, self-distraction, and self-blame.

The Brief COPE demonstrated concurrent and predictive validity in a psychiatric sample. ${ }^{27}$ Another study $^{28}$ with a sample of patients with BD I reported high internal consistency for the two subscales examined (acceptance $=0.84$; denial $=0.77$ ). The internal consistency for all subscales in that sample ranged from 0.3 to 0.9 . The Brief COPE has been successfully utilized in $\mathrm{BD}$, with good psychometric properties. ${ }^{13,28}$

In another sample, ${ }^{29}$ where 92 bipolar patients were included, all subscales demonstrated good internal consistency $(a \geq 0.60)$, except positive reframing, acceptance, self-distraction, and venting ( $a=0.53,0.58,0.17$, and 0.51 , respectively), which were excluded. All other internal consistencies were good (a ranging from 0.68 to 0.91 ). The adaptive and maladaptive domains were recalculated accordingly and demonstrated good reliability in that sample ( $a=0.82$ and 0.79 , respectively).

\section{Statistical analysis}

The Statistical Package for the Social Sciences (SPSS) version 21.0 for Windows was used to compile and analyze the data. The normality of variables was verified using the Kolmogorov-Smirnov test. Quantitative variables were expressed as means and standard deviations or medians and interquartile ranges, depending on normality, and categorical variables were expressed as relative frequencies. Differences between groups were tested using analysis of variance (ANOVA) and Tukey or the Kruskal-Wallis test for variables with normal and asymmetrical distributions, respectively. Bonferroni correction was applied where necessary. Categorical variables were analyzed using the chisquare test $\left(\mathrm{X}^{2}\right)$ or Fisher's exact test, when appropriate. Associations between variables were evaluated using Spearman's correlation coefficients. For all analyses, the limit of statistical significance was set at 0.05 .

\section{Results}

\section{Characteristics of the sample}

A total of 36 patients with BD, 39 of their firstdegree relatives and 44 controls were included. In 
all three groups, there was a majority of women: they accounted for $75 \%$ of the patients, $69 \%$ of the relatives, and $55 \%$ of the control group. Table 1 lists the characteristics of the sample.

\section{Adaptive coping vs. maladaptive coping}

The sums of the scores obtained for adaptive coping and for maladaptive coping both exhibited normal distributions, and ANOVA detected differences between the groups (patients, patients' relatives and controls) for adaptive $(p<0.001)$ and maladaptive $(p<0.001)$ scores, as shown in Table 2. After application of the
Tukey post-hoc test, significant differences were observed for adaptive coping between patients and patients' relatives $(p<0.001)$ and between patients and controls $(p=0.003)$, with patients' relatives and controls exhibiting higher scores for adaptive coping than patients. There was no significant difference between patients' relatives and controls $(p=0.707)$.

In contrast, patients $(p<0.001)$ and their relatives $(p=0.004)$ exhibited higher scores for maladaptive coping than controls. There was no significant difference when patients were compared with patients' relatives $(p=0.517)$.

Table 1 - Characteristics of the sample

\begin{tabular}{|c|c|c|c|c|c|}
\hline & Patients & Relatives & Control & Test-value & p-value \\
\hline Gender, n (\%) & & & & 4.017 & $0.134 *$ \\
\hline Male & $9.0(25.0)$ & $12.0(30.8)$ & $20.0(45.5)$ & & \\
\hline Female & $27.0(75.0)$ & $27.0(69.2)$ & $24.0(54.5)$ & & \\
\hline Marital status, $\mathrm{n}(\%)$ & & & & 11.345 & $0.078 *$ \\
\hline Single & $5.0(13.9)$ & $5.0(12.8)$ & $11.0(25.0)$ & & \\
\hline Married/partner & $17.0(47.2)$ & $24.0(61.5)$ & $28.0(63.6)$ & & \\
\hline Separated/divorced & $10.0(27.8)$ & $5.0(12.8)$ & $3.0(6.8)$ & & \\
\hline Widow & $4.0(11.1)$ & $3.0(7.7)$ & $1.0(2.3)$ & & \\
\hline Not reported & - & $2.0(5.1)$ & $1.0(2.3)$ & & \\
\hline Occupation, n (\%) & & & & 36.224 & $<0.001^{+}$ \\
\hline Student & $1.0(2.8)$ & $1.0(2.6)$ & $3.0(6.8)$ & & \\
\hline Paid work & $14.0(38.9)$ & $16.0(41.0)$ & $30.0(68.0)$ & & \\
\hline No occupation and not retired & $5.0(13.9)$ & $1.0(2.6)$ & $2.0(4.5)$ & & \\
\hline Housewife & $7.0(19.4)$ & $5.0(12.8)$ & $3.0(6.8)$ & & \\
\hline Sick leave & $3.0(8.3)$ & - & $1.0(2.3)$ & & \\
\hline Disability retiree & $6.0(16.7)$ & $2.0(5.1)$ & $1.0(2.3)$ & & \\
\hline Retired because of time in employment & - & $12.0(30.8)$ & $4.0(9.1)$ & & \\
\hline Not reported & - & $2.0(5.1)$ & - & & \\
\hline Age, mean $\pm S D$ & $47.25 \pm 10.17$ & $49.76 \pm 14.44$ & $45.84 \pm 12.16$ & 1.033 & $0.359^{\neq}$ \\
\hline Age at first episode, mean \pm SD & $27.80 \pm 10.49$ & - & - & - & - \\
\hline Age at diagnosis, mean \pm SD & $35.43 \pm 8.92$ & - & - & - & - \\
\hline$\Sigma$ & 36 & 39 & 44 & - & - \\
\hline
\end{tabular}

$\mathrm{SD}=$ standard deviation.

* Chi-square test; ${ }^{\dagger}$ Fisher exact test; ${ }^{\ddagger}$ ANOVA.

Table 2 - Coping strategies by group

\begin{tabular}{|c|c|c|c|c|c|c|}
\hline Coping & $\begin{array}{c}\text { Patient }(n=36) \\
\text { mean } \pm S D\end{array}$ & $\begin{array}{c}\text { Relative } \\
(n=39), \\
\text { mean } \pm \text { SD }\end{array}$ & $\begin{array}{c}\text { Control }(n=44) \\
\text { mean } \pm \text { SD }\end{array}$ & $\begin{array}{c}\text { p-value* } \\
\text { patients vs. } \\
\text { controls }\end{array}$ & $\begin{array}{c}\text { p-value* } \\
\text { patients vs. } \\
\text { relatives }\end{array}$ & $\begin{array}{c}\text { p-value* } \\
\text { relatives vs. } \\
\text { controls }\end{array}$ \\
\hline Adaptive & $43.35 \pm 6.32$ & $48.94 \pm 4.91$ & $47.88 \pm 6.18$ & 0.003 & $<0.001$ & - \\
\hline Maladaptive & $25.15 \pm 4.35$ & $24.03 \pm 4.77$ & $20.91 \pm 3.62$ & $<0.001$ & - & $0 ; 004$ \\
\hline
\end{tabular}

$\mathrm{SD}=$ standard deviation.

* ANOVA and Tukey test. 


\section{Coping strategies used and comparisons between groups}

Table 3 lists the results obtained for the coping strategies used by the three groups. There were significant differences in the use of the following adaptive strategies: active coping $(p<0.002)$, planning $(p<0.001)$, positive reframing $(p<0.001)$, and humor $(p<0.013)$. Differences were found between patients' relatives and patients, with patients' relatives exhibiting significantly higher mean scores than patients, for the following strategies: active coping $(p=0.011)$, planning $(p<0.001)$, positive reframing $(p<0.001)$, and humor $(p=0.031)$. There were also significant differences between patients and controls for the same strategies: active coping $(p=0.002)$, planning $(p<0.001)$, positive reframing $p=0.002)$, and humor $(p=0.035)$, in all of which controls had higher scores than patients.

Significant differences in the results obtained for maladaptive coping were identified for the strategies denial $(p<0.001)$, self-distraction $(p=0.032)$, and behavioral disengagement $(p<0.001)$. After analysis, differences were identified between patients and controls, with patients exhibiting higher scores than controls for denial $(p<0.001)$, self-distraction $(p=0.05)$, and behavioral disengagement $(p<0.001)$. Substance use was the only coping strategy that was not reported by the control group, while patients' relatives and patients did not differ from each other $(p=0.664)$.
As secondary outcomes, we explored correlations between specific types of coping and clinical variables such as gender, age at first episode, educational level, occupation and time since disease diagnosis. Correlations were detected between coping and gender and between coping and age at first episode.

\section{Coping and type of first episode}

It was observed that $33.3 \%$ of the patients' first episode was manic, and $63.9 \%$ had had a first episode that was depressive. Analysis of the correlations between first episode subtype (manic vs. depressive) and coping strategies revealed significant differences for positive reframing, in that the subset of patients whose first episode was manic had higher scores (6.42) than the subset of patients whose first episode was depressive, with a mean score of 5.29 , resulting in $p=0.042$.

When age at first episode was analyzed, there was a significant difference for the acceptance strategy $\left(r_{s}=0.400\right.$, $p=0.019)$. There was also an inverse relationship between age at first episode and venting $\left(r_{s}=-0.381, p=0.026\right)$. There were no further differences between patients with a manic vs. a depressive first episode in terms of any of the other types of coping. Similarly, there were no significant differences when coping was classified as adaptive or maladaptive. None of the other variables assessed (age, educational level, occupation) exhibited statistically significant correlations with coping.

Table 3 - Coping style

\begin{tabular}{|c|c|c|c|c|}
\hline Coping & $\begin{array}{l}\text { Patients }(n=36), \\
\text { median }\left(\mathrm{p}_{25}-\mathrm{p}_{75}\right)\end{array}$ & $\begin{array}{l}\text { Relatives }(n=39), \\
\text { median }\left(p_{25}-p_{75}\right)\end{array}$ & $\begin{array}{l}\text { Controls }(n=44), \\
\text { median }\left(p_{25}-p_{75}\right)\end{array}$ & p-value* \\
\hline \multicolumn{5}{|l|}{ Adaptive } \\
\hline Active coping & $6.0(5.0-7.0)$ & $7.0(6.0-8.0)$ & $7.0(6.0-8.0)$ & $0.002^{+\neq}$ \\
\hline Planning & $6.0(5.0-7.0)$ & $7.0(6.0-8.0)$ & $7.0(6.0-8.0)$ & $<0.001^{\dagger \neq}$ \\
\hline Use of instrumental support & $5.0(3.0-6.0)$ & $5.0(3.75-6.0)$ & $6.0(5.0-6.0)$ & 0.267 \\
\hline Use of emotional support & $6.0(4.0-7.5)$ & $5.5(4.0-7.0)$ & $5.0(4.0-6.0)$ & 0.458 \\
\hline Religion & $6.0(4.0-8.0)$ & $7.0(5.0-8.0)$ & $6.0(4.0-8.0)$ & 0.281 \\
\hline Positive reframing & $6.0(5.0-7.0)$ & $8.0(6.75-8.0)$ & $7.0(6.0-8.0)$ & $<0.001^{\text {t† }}$ \\
\hline Acceptance & $6.0(5.0-6.5)$ & $6.0(5.0-7.0)$ & $6.0(5.0-7.0)$ & 0.164 \\
\hline Humor & $4.0(3.0-5.0)$ & $5.5(4.0-7.0)$ & $5.0(4.0-6.0)$ & $0.013^{+\neq}$ \\
\hline \multicolumn{5}{|l|}{ Maladaptive } \\
\hline Self-blame & $4.0(3.0-6.0)$ & $4.0(3.0-5.25)$ & $4.0(3.0-5.0)$ & 0.913 \\
\hline Venting & $6.0(4.0-7.0)$ & $6.0(4.75-7.0)$ & $4.0(4.0-6.0)$ & 0.079 \\
\hline Denial & $4.0(4.0-6.0)$ & $4.0(3.0-5.0)$ & $3.0(2.0-4.0)$ & $<0.001^{+}$ \\
\hline Self-distraction & $5.0(4.0-6.0)$ & $5.0(3.0-5.0)$ & $4.0(3.0-5.0)$ & $0.032^{+}$ \\
\hline Behavioral disengagement & $3.0(3.0-5.0)$ & $3.0(2.0-4.0)$ & $2.0(2.0-4.0)$ & $<0.001^{+}$ \\
\hline Substance use ${ }^{\S}$ & $2.0(2.0-2.0)$ & $2.0(2.0-2.0)$ & 0 & - \\
\hline
\end{tabular}

* Independent Kruskal-Wallis and Bonferroni.

Difference ${ }^{+}$between patients and controls and ${ }^{*}$ between patients and relatives.

$\S$ No p-value calculated because zero controls reported substance use 


\section{Discussion}

Our findings show that there are differences in the use of adaptive and maladaptive strategies between patients, patients' relatives and controls. Whereas patients were less likely to use adaptive strategies, controls and the patients' relatives did not differ in this respect. In contrast, both patients as well as their firstdegree relatives reported greater use of maladaptive strategies in comparison to controls.

The observation that first-degree relatives and controls use adaptive strategies more than patients has been reported in previous studies ${ }^{13,14}$ and suggests that the capacity of patients' relatives to manage stressful situations using more adaptive strategies is due to the lack of functional impairment associated with BD, or that their better capacity is protective against the development of mental disorders.

In contrast, results for maladaptive strategies revealed that both patients' relatives and the patients themselves used these strategies more frequently than healthy controls. One possibility is that family environments with high levels of conflict, impaired emotional expression and emotional overload may contribute to less effective management of stressful situations. ${ }^{30}$

These findings show that patients' relatives appear to form an intermediate group in relation to patients and controls, highlighting the importance of providing patients' relatives with psychological care, since a dysfunctional family environment is associated with precipitation, recurrence and relapse in many different psychiatric disorders. Moreover, it is known that the family can be a protective factor or a risk factor for disease progression, depending on how conflicts are resolved. ${ }^{1}$

The greater use of maladaptive strategies by patients than by controls may be associated with the cognitive deterioration that can occur in bipolar patients with long disease duration and recurrent episodes. ${ }^{31}$ Coping strategies are dependent on the integrity of executive function, and a long-lasting disease process can lead to the ineffective use of coping strategies and consequent adoption of mechanisms that are less effective for the management of stressful situations. ${ }^{12}$

In $\mathrm{BD}$, functioning can be improved, and life satisfaction increased, through psychosocial interventions, ${ }^{32}$ techniques such as self-monitoring, identification of early signs of relapse and methods for managing adverse situations and stressful events, ${ }^{33}$ contributing to a more effective use of adaptive strategies.

The more frequent use of the strategies active coping (take action or make an effort to remove the source of stress), planning (think about ways of dealing with the stressor, planning active coping efforts), positive reframing (making the best of a situation and growing through it or seeing it in a more favorable light) and humor (making a joke out of the stress factor) by patients' relatives provides indications of preserved cognitive function that could play a protective role against the development of psychiatric disorders.

The more frequent use by the patients of strategies such as denial (attempts to reject the reality of the stressful event), self-distraction (mental disengagement from the objective with which the stressor is interfering, through daydreaming, sleeping or self-destruction) and behavioral disengagement (giving up on or abandoning efforts to attempt to attain the objective with which the stressor is interfering) indicates a reduced capacity to manage adverse situations that may be related to cognitive deterioration caused by disease duration.

Patients were less likely to have an occupation than controls, which suggests functional impairment caused by the disorder. Even with their symptoms stabilized, patients with $\mathrm{BD}$ exhibit greater difficulty managing the activities of their daily life, such as working regularly, maintaining relationships and involving themselves in family life. ${ }^{34,35}$

Analysis of the type of first episode showed that patients who had had a manic first episode were more likely to use positive reframing strategies than patients who had had a depressive first episode. Other coping strategies were not correlated with subtype of first episode. A review study of coping in affective disorders did not find specific associations between coping strategies and type of first episode. ${ }^{10}$

In turn, use of the acceptance coping strategy was directly related to age at first episode: the greater the patients' age at first episode, the more likely they were to employ acceptance coping. This type of coping is an adaptive strategy and comprises accepting that the stressful event has happened and is real, indicating greater awareness of the situation, which is needed to face up to it. This strategy is also linked to compliance with medication, since low scores appear to be associated with poor compliance with medication. ${ }^{28}$

In contrast, the use of venting exhibited an inverse relationship with age at first episode, indicating that the younger the age at first episode, the greater the frequency of venting coping. This strategy involves heightened awareness of emotional stress and a tendency to express or offload these feelings, and is considered a maladaptive strategy. This finding could suggest that this strategy is related to maturity and that the earlier in life that patients are affected by the mental disorder, the greater their use of emotional venting in response to stress.

Based on the results found, the prevalence of maladaptive coping strategies in patients and 
relatives suggests that psychological techniques should be used to assist them in the management of stress situations.

One of the objectives of psychosocial interventions is to increase the capacity to deal with environmental stressors associated with the symptomatology of BD. The use of stress reduction techniques, helping patients and their families to modify the evaluation of stressful situations, can contribute to an emotional improvement. Psychosocial interventions that are specific for the treatment of BD (in addition to regular follow-up and support care) offer additional benefits, not only for the patient but also for the setting and health care professionals in general. ${ }^{2}$

This study has compiled relevant data that should make a contribution to the understanding of the psychological factors associated with the course of $B D$ and the observation of first-degree relatives who do not develop the disease. The study also contributes to a better understanding of coping strategies and their importance in the context of BD. Notwithstanding, there is a need to explore more specific strategies using prospective studies in order to understand coping throughout the course of the disease. Longitudinal studies employing psychological and clinical assessments allow the changes in participants' psychological patterns to be better mapped, thereby further facilitating understanding of the role played by cognitive processes in bipolar symptoms. Along the same lines, interventions employing psychotherapy to improve patients' coping strategies to help them control their disease also merit further investigation.

The size of the sample is an important limiting factor, and the results should be interpreted with care. Another limitation is the fact that the Brief COPE version employed was adapted to European rather than to Brazilian Portuguese, and there may be cultural differences implied. The lack of a validation study for this version of the scale is another important limitation. It is necessary to investigate coping processes in conjunction with other psychological factors in prospective studies, which would provide greater understanding of the importance of coping in the development of BD. It is not easy to make a clear distinction between coping processes and symptoms without a better understanding of the complex interaction involved. Because of these difficulties, psychosocial interventions focusing on coping strategies still need to be better formulated and studied. High-risk long-term studies capable of detecting coping before and after the onset of a mood disorder would aid in the production of new information on the relationship between coping strategies and mood disorder. ${ }^{10}$

\section{Conclusion}

In conclusion, the group of patients' relatives was at an intermediate level between patients and controls. Patients' relatives reported using adaptive strategies more often, which could contribute to better emotional equilibrium, but they also reported a greater frequency of using maladaptive strategies, at a similar level to that reported by patients, meaning that they remain part of a group that is less effective at managing stressful situations, which could contribute to the development of psychological disorders. Better psychosocial interventions to foster the more frequent use of adaptive rather than maladaptive strategies are certainly needed.

\section{Acknowledgements}

This study received financial support from Fundo de Incentivo à Pesquisa e Eventos - Hospital de Clínicas de Porto Alegre (FIPE-HCPA).

Adam Fijtman and Keila Maria Mendes Ceresér have received grants from Coordenação de Aperfeiçoamento de Pessoal de Nível Superior (CAPES). Márcia KauerSant'Anna has received grants from Conselho Nacional de Desenvolvimento Científico e Tecnológico (CNPq), CAPES, and FIPE-HCPA.

\section{Disclosure}

Márcia Kauer-Sant'Anna has received grants from Eli Lilly and Novartis. Mauricio Kunz has received personal fees from Daiichi Sankyo. No other conflicts of interest declared concerning the publication of this article.

\section{References}

1. Miklowitz DJ, Johnson SL. Social and familial factors in the course of bipolar disorder: basic processes and relevant interventions. Clin Psychol. 2009;16:281-96.

2. Lolich M, Vazquez GH, Alvarez LM, Tamayo JM. Psychosocial interventions in bipolar disorder: a review. Actas Esp Psiquiatr. 2012:40:84-92.

3. Sanchez-Moreno J, Martinez-Aran A, Tabarés-Seisdedos R, Torrent C, Vieta E, Ayuso-Mateos JL. Functioning and disability in bipolar disorder: an extensive review. Psychother Psychosom. 2009;78:285-97.

4. Lafer B, Soares J, Sanches M, Del Porto J. Transtorno bipolar: da genética à reabilitação psicossocial. Rev Bras Psiquiatr. 2004;26:1-2.

5. Malkoff-Schwartz SE, Anderson B, Sherrill JT, Siegel L, Patterson $D$, Kupfer DJ. Stressful life events and social rhythm disruption in the onset of manic and depressive bipolar episodes. Arc Gen Psychiatry. 1998;55:702-7.

6. Lazarus RS, Folkman S. Stress appraisal and coping. New York: Springer; 1984. 
7. Boschi S, Adams RE, Bromet EJ, Lavelle JE, Everett E, Galambos N. Coping with psychotic symptoms in the early phases of schizophrenia. Am J Orthopsychiatry. 2000;70:242-52.

8. Nolen-Hoeksema S. The role of rumination in depressive disorders and mixed anxiety/depressive symptoms. J Abnormal Psychol. 2000;109:504-11.

9. Greenhouse WJ, Meyer B, Johnson SL. Coping and medication adherence in bipolar disorder. J Affect Disord. 2000;59:237-41.

10. Christensen MV Kessing LV. Clinical use of coping in affective disorder, a critical review of the literature. Clin Pract Epidemiol Ment Health. 2005;1:20-8.

11. Lam D, Wong G, Sham P. Prodromes, coping strategies and course of illness in bipolar affective disorder - a naturalistic study. Psychol Med. 2001;31:1397-402.

12. Grassi-Oliveira R, Daruy-Filho L, Brietzke E. New perspectives on coping in bipolar disorder. PsycholNeurosci. 2010;3:161-5.

13. Fletcher K, Parker GB, Manicavasagar V. Coping profiles in bipolar disorder. Compr Psychiatry. 2013;54:1177-1184.

14. Goossens PJ, Knoppert-van der Klein EA, van Achterberg T. Coping styles of outpatients with a bipolar disorder. Arch Psychiatr Nurs. 2008;22:245-53.

15. Green MJ, Lino BJ, Hwang EJ, Sparks A, James C, Mitchell PB. Cognitive regulation of emotion in bipolar I disorder and unaffected biological relatives. Acta Psychiatr Scand. 2011;124:307-16.

16. Kessler RC, McGonagle KA, Zhao S, Nelson CB, Hughes M, Eshleman $S$, et al. Lifetime and 12-month prevalence of DSMIII-R psychiatric disorders in the United States. Results from the National Comorbidity Survey. Arch Gen Psychiatry. 1994;51:819.

17. Chadda RK, Singh TB, Ganguly KK. Caregiver burden and coping: A prospective study of relationship between burden and coping in caregivers of patients with schizophrenia and bipolar affective disorder. Soc Psychiatry Psychiatr Epidemiol. 2007;42:923-30.

18. Heru AM, Ryan CE. Burden, reward and family functioning of caregivers for relatives with mood disorders: 1-year follow-up. J Affect Disord. 2004;83:221-5.

19. Ogilvie $A D$, Morant $M$, Goodwin GM. The burden on informal caregivers of people with bipolar disorder. Bipolar Disord. 2005;7(Suppl 1): 25-32.

20. Stern M, Zevon MA. Stress, coping, and family environment: the adolescent's response to naturally occurring stressors. J Adolescent Res. 1990;5:290-305.

21. Nijjar R, Ellenbogen MA, Hodgins S. Personality, coping, risky behavior, and mental disorders in the offspring of parents with bipolar disorder: A comprehensive psychosocial assessment. J Affect Disord. 2014;166:315-23.

22. Parikh SV, Velyvis V, Yatham L, Beaulieu S, Cervantes $P$, Macqueen $\mathrm{G}$, et al. Coping styles in prodromes of bipolar mania. Bipolar Disord. 2007; 9:589-595.
23. Carver CS, Scheier MF. Attention and self-regulation: A controltheory approach to human behavior. New York: Springer-Verlag; 1981.

24. Ribeiro J, Rodrigues A. Questões acerca do coping: A propósito do estudo de adaptação do Brief COPE. Psicol Saude Doenças. 2004; 5:3-15.

25. Carver $C$, Scheier M, Weintraub J. Assessing coping strategies: A theoretically based approach. J Pers Soc Psychol. 51989;6:26783.

26. Carver CS. You want to measure coping but your protocol's too long: consider the Brief COPE. Int J Behav Med. 1997;4:92-100.

27. Meyer B. Coping with severe mental illness: relations of the Brief COPE with symptoms, functioning, and well-being. J Psychopathol Behav Assess. 2001;4:265-77.

28. Greenhouse WJ, Meyer B, Johnson SL. Coping and medication adherence in bipolar disorder. J Affect Disord. 2000;59:237-41.

29. Nitzburg GC, Russo M, Cuesta-Diaz A, Ospina L, Shanahan $M$, Perez-Rodriguez $M$, et al. Coping strategies and real-world functioning in bipolar disorder. J Affect Disord. 2016;198:185-8.

30. Jones SH, Bentall RP. A review of potential cognitive and environmental risk markers in the children of bipolar parents. Clin Psychol Rev. 2008;28:1083-95.

31. Kapczinski $F$, Vieta $E$, Andreazza AC, Frey BN, Gomes FA, Tramontina J, et al. Allostatic load in bipolar disorder: implications for pathophysiology and treatment. Neurosci Biobehav Rev. 2008;32:675-92.

32. Miklowitz D, Otto M. Psychosocial interventions for bipolar disorder: A review of literature and introduction of the systematic treatment enhancement program. Psychopharmacol Bull. 2007;40:116-31.

33. Reinares M, Colom F, Sánchez-Moreno J, Torrent C, Martínez-Arán $A$, Comes $M$, et al. Impact of caregiver group psychoeducation on the course and outcome of bipolar patients in remission: A randomized controlled trial. Bipolar Disord. 2008;10:511-9.

34. Folkman S, Lazarus RS. If it changes it must be a process: A study of emotion and coping during three stages of a college examination. J Pers Soc Psychol. 1985;48:150-70.

35. Folkman S, Lazarus RL, Dunkel-Schetter C, DeLongis A, Gruen R. Dynamics of a stressful encounter: Cognitive appraisal, coping, and encounter outcomes. J Pers Soc Psychol. 1986;50:9921003.

\section{Correspondence:}

Maurício Kunz

Laboratório de Psiquiatria Molecular, Hospital de Clínicas de Porto Alegre, Universidade Federal do Rio Grande do Sul

Rua Ramiro Bacelos, 2350

90035-903 - Porto Alegre, RS, Brazil

E-mail: maukunz@gmail.com 


\section{http:/ / dx.doi.org/10.1590/2237-6089-2019-0001}

The authors of the article entitled "Differences in coping strategies in adult patients with bipolar disorder and their first-degree relatives in comparison to healthy controls" (doi: http://dx.doi.org/10.1590/2237-6089-2017-0140), published in Trends in Psychiatry and Psychotherapy, 2018, volume 40, issue 4, pages 318-325, have identified an error in the name of an author. "Adam Fitjman" should read "Adam Fijtman." Here we reproduce the final, correct version of the author byline:

Kelen Patrícia Bürke Bridi, Ana Claudia M. Loredo-Souza, Adam Fijtman, Mirela Vasconcelos Moreno, Márcia Kauer-Sant'Anna, Keila Maria Mendes Ceresér, Mauricio Kunz

Bridi KPB, Loredo-Souza ACM, Fijtman A, Moreno MV, Kauer-Sant'Anna M, Ceresér KMM, Kunz M.

Trends Psychiatry Psychother. 2019;41(1):103. 